\title{
Anatomic Asymmetry of lliolumbar Artery in Goan Population: A Cross-sectional Study
}

\section{ABSTRACT}

Introduction: Haemorrhage is one of the most common complications in laparoscopic pelvic and para-aortic surgeries thus making variant anatomy of Iliolumbar Artery (ILA) important as it is one of the vessels leading to haemorrhage.

Aim: To study variant anatomy of ILA and its morphometric analysis.

Materials and Methods: A cross-sectional study was done over a period of five months from January 2020 to May 2020. Twentyseven-formalin fixed human pelvises were dissected in iliolumbar region in the dissection hall of the Department of Anatomy, Goa Medical College, Bambolim, Goa, India. Point of origin of lliolumbar Artery (ILA), its length before its branches, distance from the branching of Internal Iliac Artery (IIA) and Common Iliac Artery $(\mathrm{CIA})$ trunk were evaluated. The length of these vessels was measured by using a thread and a vernier caliper (sensitive to $0.1 \mathrm{~mm}$ ) by following their curves.
Results: The ILA was found to originate from IIA (trunk) in twenty-one (38.89\%); from posterior division of the IIA in eight (14.81\%); at the division of IIA in fifteen (27.78\%); from CIA (trunk) in two $(3.70 \%)$ and was not traceable (was not found branching from IIA) in eight (14.81\%) specimen. Mean length of ILA when originating from posterior division of IIA was $1.36 \pm 0.44 \mathrm{~cm}$; when originating from IIA (trunk) was $1.53 \pm 0.46 \mathrm{~cm}$ and when originating at the division of IIA was $1.64 \pm 0.67 \mathrm{~cm}$. Mean distance of ILA from IIA if ILA originates from IIA (trunk) was $2.27 \pm 0.81 \mathrm{~cm}$ and if ILA originates from posterior division of IIA was $1.23 \pm 0.57 \mathrm{~cm}$. Mean distance of ILA from CIA (trunk) if ILA originates from IIA (trunk) was $2.53 \pm 1.07 \mathrm{~cm}$, if ILA originates from posterior division of IIA was $3.95 \pm 1.06 \mathrm{~cm}$.

Conclusion: Knowledge of anatomy and variations of the ILA to the modern day laparoscopic surgeons, orthopaedic spine surgeons and vascular surgeons will immensely help in safe surgical outcomes.

\section{INTRODUCTION}

Laparoscopic pelvic and para-aortic surgeries, pelvic fractures due to high-energy trauma, injury to posterior pelvic segment and surgeries in the iliolumbar region can damage IIA and its branches, hence variant anatomy of the IIA is important for surgeons dealing with pelvic surgeries $[1,2]$. ILA classically arises as the first branch of the posterior division of the IIA. Thereafter, it laterally ascends running anterior to the sacroiliac joint and nerve trunk of the lumbosacral region. In relation to the obturator nerve and external iliac vessels, it lies posteriorly and upon reaching the medial border of the psoas major muscle, the ILA divides into iliac and lumbar branches behind this muscle [3]

Psoas major and quadratus lumborum is supplied by the lumbar branches of ILA and later it anastomoses with the fourth lumbar artery. It also supplies cauda equina by its spinal branches traversing through the intervertebral foramina. lliac branches supply iliacus and anastomose with the iliac branches of the obturator artery. The branch from ILA forms the nutrient artery. Remaining branches are oriented around the iliac crest and anastomose with the neighbouring arteries [3]

According to a previous study on thirty human adult pelvic halves, the origin of ILA was classified as; level A-arising from the CIA (8.57\%); level B-from CIA bifurcation (2.5\%); level C-from IIA trunk (52.5\%); level D- from IIA bifurcation (3.75\%); level E-from posterior trunk of IIA (32.5\%) [4]. Developmentally, the IIA passes through several stages of development and is derived from the umbilical artery. After birth the proximal part of the umbilical artery persists whereas the distal part gets obliterated [5].

Goa Medical College being the only medical college in the state of Goa and being the only government medical college where laparoscopic surgeries are undertaken, have encouraged us to take up this research work so as to help the young laparoscopic surgeons, orthopaedic spine surgeons and vascular surgeons to give them insight about the possible variations and asymmetry of ILA as found in Goan population and prepare them for their future surgeries.

\section{MATERIALS AND METHODS}

This cross-sectional study was conducted in the dissection hall of the Department of Anatomy, Goa Medical College, Bambolim, Goa, over a period of five months from January 2020 to May 2020; however, these specimens have been examined during an earlier study on aberrant obturator artery [6] and were collected over a period of five years for the same. Twenty-seven formalinfixed pelvises (54 paired hemi pelvises) of adult cadavers were dissected, irrespective of sex. Institutional Ethics Committee (IEC) permission (GMC/IEC/2020/23) was taken for dissecting these formalin-fixed pelvises.

Inclusion criteria: Specimens from cadavers of Goan origin (verified origin as per records), having intact pelvic vasculature were selected for this study.

Exclusion criteria: Specimens showing gross carcinomatous changes, traumatised pelvises, any previous pelvic surgical manipulations which may affect the result of the study were excluded from the study.

\section{Study Procedure}

The fifty-four hemi pelvises were carefully examined for any of the above mentioned exclusion criteria. Dissection includes clearing of the dissection field by removal of all the tributaries of the Internal lliac Vein (IIV) since it is typically plexiform. The next step was to identify the CIA and follow it distally till its bifurcation into IIA and EIA. Using blunt dissection, IIA was traced till the pelvis where it bifurcated into an anterior division and a posterior division. The ILA was identified arising from the posterior division of IIA. Its course was traced going 
posteriorly and ascending between the lumbosacral trunk and the obturator nerve as can be seen in [Table/Fig-1] [7].

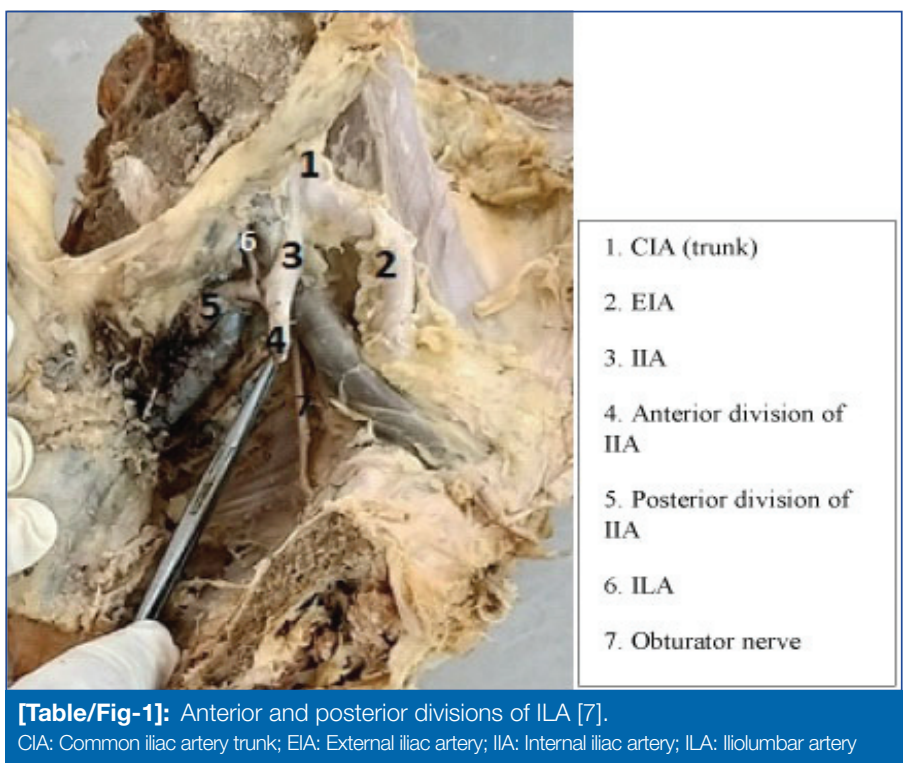

After successful identification of the ILA from all the specimen, the morphological and morphometric parameters were studied, which included identification of the point of origin of the ILA, the measurement of its length before it gives off its branches and distance from the division of IIA and CIA. The lengths of these vessels were measured by using a thread and a vernier caliper (which was sensitive to $0.1 \mathrm{~mm}$ ) by following their curves. Along with the ILA, CIA, EIA and IIA were also dissected. Photographs were taken using a sony alpha camera with the zoom lens.

\section{STATISTICAL ANALYSIS}

Data was entered into Microsoft Excel spreadsheet, later the descriptive statistics including number and percentage for categorical data and mean \pm standard deviation for continuous data was analysed using statistical software SPSS version 22.0.

\section{RESULTS}

Taking into consideration [Table/Fig-2-5] the results were divided into four groups:

1. Arteries giving origin to the ILA.

2. Mean length of ILA.

3. Mean distance of ILA from IIA (origin).

4. Mean distance of ILA from CIA (origin).

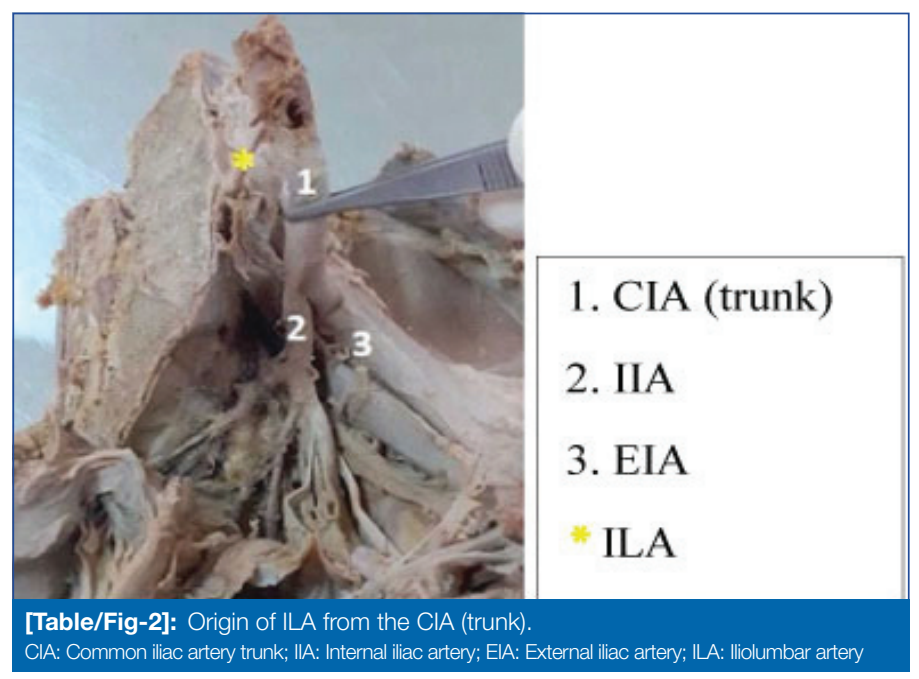

\section{Arteries Giving Origin to ILA}

In [Table/Fig-6] the various sites of origin of ILA, number of specimens showing the specific origin and the mean length of ILA from the
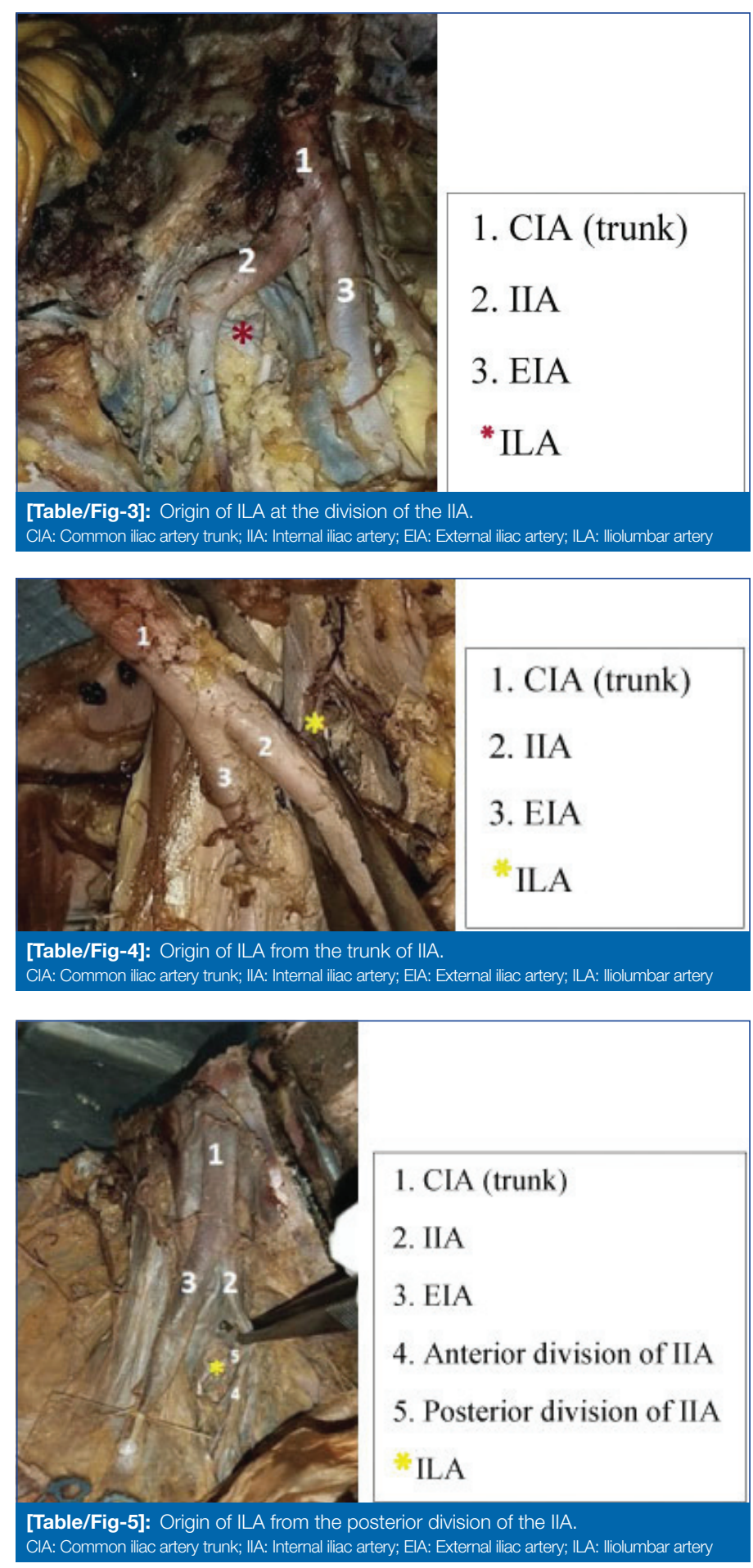

artery of origin are tabulated. Origin of ILA was seen from IIA (trunk) [Table/Fig-4], posterior division of IIA [Table/Fig-5], at the division of IIA [Table/Fig-3], CIA (trunk) [Table/Fig-2] and in some specimens ILA was not traceable (was not found branching from IIA).

Out of fifty-four hemipelvises twenty-one hemipelvises (38.89\%) had the origin of ILA from the IIA (trunk) and only two (3.71\%) hemipelvises branched from CIA (trunk).

\begin{tabular}{|l|c|c|c|}
\hline Artery of origin & $\begin{array}{c}\text { No. of } \\
\text { samples }(\mathrm{n})\end{array}$ & Percentage & $\begin{array}{c}\text { Mean length of ILA from } \\
\text { the artery of origin }(\mathrm{cm})\end{array}$ \\
\hline IIA (trunk) & 21 & 38.89 & $1.53 \pm 0.46$ \\
\hline Posterior division of IIA & 8 & 14.81 & $1.36 \pm 0.44$ \\
\hline At the division of IIA & 15 & 27.78 & $1.64 \pm 0.67$ \\
\hline CIA (trunk) & 2 & 3.71 & $1.73 \pm 0.74$ \\
\hline${ }^{*}$ Not traceable & 8 & 14.81 & - \\
\hline Total & 54 & 100 & \\
\hline
\end{tabular}

[Table/Fig-6]: Incidence of origin and mean length from the artery of origin of ILA. "was not found branching from IIA 


\section{Mean Length of ILA}

Length of ILA from the artery of origin was found to vary between $1.36-1.73 \mathrm{~cm}$. As seen in [Table/Fig-6].

\section{Mean Distance of ILA from IIA (origin) and CIA (origin)}

Mean distance of ILA (according to the artery of origin) from IIA (origin) and CIA (origin) is tabulated in [Table/Fig-7]. The distance was found to range in between $1.23-3.95 \mathrm{~cm}$.

Table/Fig-8] represents the pattern of origin of ILA on either side of the pelvis.

\begin{tabular}{|c|c|c|}
\hline Artery of origin & $\begin{array}{l}\text { Mean distance from the } \\
\text { IIA origin }(\mathrm{cm})\end{array}$ & $\begin{array}{l}\text { Mean distance from } \\
\text { the CIA origin }(\mathrm{cm})\end{array}$ \\
\hline IIA (trunk) & $2.27 \pm 0.81$ & $2.53 \pm 1.07$ \\
\hline Posterior division of IIA & $1.23 \pm 0.57$ & $3.95 \pm 1.06$ \\
\hline
\end{tabular}

\begin{tabular}{|l|c|c|c|c|}
\hline \multirow{2}{*}{ Artery of origin } & \multicolumn{4}{|c|}{ Number of hemipelvises and percentage } \\
\cline { 2 - 5 } & $\begin{array}{c}\text { Number of right } \\
\text { hemipelvis }(\mathrm{n})\end{array}$ & Percentage & $\begin{array}{c}\text { Number of left } \\
\text { hemipelvis }(\mathrm{n})\end{array}$ & Percentage \\
\hline IIA (trunk) & 7 & 25.93 & 14 & 51.86 \\
\hline $\begin{array}{l}\text { Posterior division } \\
\text { of IIA }\end{array}$ & 5 & 18.52 & 3 & 11.11 \\
\hline $\begin{array}{l}\text { At the division } \\
\text { of IIA }\end{array}$ & 8 & 29.63 & 7 & 25.93 \\
\hline CIA (trunk) & 1 & 3.70 & 1 & 3.70 \\
\hline Not traceable & 6 & 22.22 & 2 & 7.40 \\
\hline
\end{tabular}

\section{DISCUSSION}

A successful surgery largely depends on thorough knowledge about the vascular system. In an earlier study on origin of the obturator artery in a Goan population, aberrant obturator artery was documented in $10 \%$ while $4 \%$ of arterial corona mortis was observed and the study concluded that knowledge of variant origin of the obturator artery and the presence of accessory or aberrant obturator arteries is of utmost importance to a laparoscopic surgeon while performing pelvic surgeries [6]. The amount of variation shown by the ILA in the present study is a reason enough to study more about the vascular system in detail.

Importance of ILA is significant due to the fact that it is situated in close proximity with the sacro-iliac joint, any trauma or fracture (open-book) due to high impact injuries may lead to laceration in the artery which may result in haemorrhage, can be encountered during anterior and anterolateral surgical procedures, in establishing collateral vasculature with deep circumflex iliac artery and lateral circumflex vessels, harvesting the free iliac bone flaps, laparoscopic common iliac and para aortic lymph node dissection and iatrogenic sciatica [8-10].

[Table/Fig-9] represents a comparison of the present study with previous studies by different authors. Absence of ILA was described in the studies conducted by Al Talawah W et al., Lipshutz B and Gadagi RS and Mulage SK, [Table/Fig-9] [9,11,12] in 5\%, 4.7\% and $26.67 \%$ of specimen, respectively. In the present study, it was found that $14.81 \%$ of specimen had a non-traceable ILA. In a recent study by Dzmitry $\vee$ and Anastasiya $B$, [Table/Fig-9] [13]. ILA was found to be originating from IIA (trunk) and posterior division of IIA unlike in the present study where it originated from IIA (trunk), posterior division of IIA, CIA (trunk) and at the division of IIA.

Since the study included paired pelvises, it gave an opportunity to compare the pattern of the vasculature on either side. As stated above $74.07 \%$ of specimen showed bilateral asymmetry. This is an eye-opening fact especially concerning the bilateral surgeries of the pelvis. Hence, a surgeon should be prepared to discover different anatomy in the same surgery as it has been proved in the present study.

\begin{tabular}{|l|c|c|c|c|c|}
\hline \multirow{2}{*}{ Authors } & \multicolumn{5}{|c|}{ Origin sites of Iliolumbar Artery (ILA) } \\
\cline { 2 - 6 } & $\begin{array}{c}\text { IIA } \\
\text { (trunk) }\end{array}$ & $\begin{array}{c}\text { Posterior } \\
\text { division } \\
\text { of IIA }\end{array}$ & $\begin{array}{c}\text { At the } \\
\text { division } \\
\text { of IIA }\end{array}$ & $\begin{array}{c}\text { CIA } \\
\text { (trunk) }\end{array}$ & $\begin{array}{c}\text { Not } \\
\text { traceable/ } \\
\text { Absent }\end{array}$ \\
\hline Lipshutz B (1981) [11] & - & - & - & - & $5 \%$ \\
\hline $\begin{array}{l}\text { Rusu MC et al., } \\
\text { (2010) [4] }\end{array}$ & $52.50 \%$ & $32.50 \%$ & $3.75 \%$ & $8.80 \%$ & - \\
\hline $\begin{array}{l}\text { Kiray A et al., (2010) } \\
\text { [14] }\end{array}$ & $71.40 \%$ & $19 \%$ & - & $4.80 \%$ & - \\
\hline $\begin{array}{l}\text { Teli CG et al., (2013) } \\
\text { [8] }\end{array}$ & $20 \%$ & $80 \%$ & - & - & - \\
\hline $\begin{array}{l}\text { Talalwah WA et al., } \\
\text { (2015) [9] }\end{array}$ & $13.80 \%$ & $77.90 \%$ & - & $2 \%$ & $4.7 \%$ \\
\hline $\begin{array}{l}\text { Koc T et al., (2016) } \\
\text { [15] }\end{array}$ & $70.60 \%$ & - & - & $29.40 \%$ & - \\
\hline $\begin{array}{l}\text { Gadagi RS and } \\
\text { Mulage SK, (2018) } \\
\text { [12] }\end{array}$ & $36.67 \%$ & $23.33 \%$ & - & $13.33 \%$ & $26.67 \%$ \\
\hline $\begin{array}{l}\text { Yuvaraj MF et al., } \\
\text { (2018) [16] }\end{array}$ & $75 \%$ & $25 \%$ & - & - & - \\
\hline $\begin{array}{l}\text { Dzmitry V and } \\
\text { Anastasiya B, (2020) } \\
\text { [13] }\end{array}$ & $16.6 \%$ & $73.3 \%$ & - & - & - \\
\hline Present study (2020) & $38.88 \%$ & $14.81 \%$ & $27.77 \%$ & $3.70 \%$ & $14.81 \%$ \\
\hline [Table/Fig-9]: Studies showing Incidence of origin of ILA [4,8,9,11-16]. \\
\hline
\end{tabular}

Taking into consideration [Table/Fig-9] $[4,8,9,11-16]$, it is clear that different researchers and specialists have found abundant variation in the origin of the ILA, hence importance should be given to variations found in the present study. The present study elaborates the possible variations in morphology and morphometry of ILA in formalin-fixed pelvic specimens and few variations which were rarely listed in the previous studies mentioned above, hence providing young surgeons as well as orthopaedic surgeons with a better knowledge of the variant anatomy of ILA.

Hence, knowledge of anatomy and variations of the ILA to the modern day laparoscopic surgeons, Orthopaedic spine surgeons and vascular surgeons will immensely help in safe surgical outcomes. This study provides an added advantage to young budding surgeons as they can visit the anatomy dissection hall to observe these vascular variations, and apply this knowledge in their surgical practice.

\section{Limitation(s)}

The availability of small number of cadaveric specimen for analysis, limited the present study.

\section{CONCLUSION(S)}

Anatomy of ILA is important for surgeons especially when there are vast variations. Variation includes point of origin of the ILA, its length before its branches, distance from the branching of IIA (trunk) and CIA (trunk). Even bilateral asymmetry as described in the present study is a noteworthy point to consider. As elaborated in the present study, most frequent origin of ILA was found to be from the IIA (trunk) followed by origin at the division of IIA; posterior division of IIA and CIA (trunk) in a decreasing order of incidence. In a few specimens, ILA was not traceable due to the reasons mentioned previously. This study even included vascular asymmetry with more specimens being bilaterally asymmetrical in their anatomy, which is vital in orthopaedics, obstetrics and gynaecology and general surgery.

\section{Acknowledgement}

The authors would like to extend their sincere regards to Dr. Professor Shivanand Bandekar, Dean of Goa Medical College and Hospitals, Goa, for giving permission to conduct the research work in the Department of Anatomy, Goa Medical College and Hospitals, Goa. 


\section{REFERENCES}

[1] Wee J, Lua W, Louange DT. Massive haemorrhage from the internal iliac artery following a low energy superior pubic ramus fracture in 73-year-old man. J Clin Trauma. 2013;4(2):98-101.

[2] Baca V, Marvanova Z, Stefela J, Hasplova K, Kachlik D, Dzupa V. Risk of bleeding from the internal iliac artery and its branches in Pelvic fractures: Cadaver study. Acta Chir Orthop Traumatol Cech. 2015;82(1):48-50.

[3] Standring S. Gray's Anatomy: The anatomical basis of clinical practice, 41 the edition. Elsevier, 2016, 1226.

[4] Rusu MC, Cergan R, Dermengiu D, Curca GC, Folescu R, Motoc AGM, et al. The lliolumbar Artery- Anatomical considerations and details on the common iliac artery trifurcation. Clin Anat. 2010;23(1):93-100.

[5] Sadler TW. Langman's Medical Embryology. 6 the Edition. London: Williams \& Wilkins, 2000, 292-293.

[6] D'Souza Dias MC, Patil RT. Anomalous origin of the obturator artery in a Goan population: A study linked with hernia reduction surgery. J Anat Soc India. 2019;68(2):105-09.

[7] Tank PW. Grant's Dissector. 15 the Edition. Philadelphia: Wolters Kluwer Health/ Lippincott Williams \& Wilkins, 2013, 143-144.

[8] Teli CG, Kate NN, Kothandaraman U. Morphometry of the iliolumbar artery and the iliolumbar vein and their correlations with the lumbosacral trunk and the obturator nerve. JCDR. 2013;7(3):422-26.
[9] Al Talalwah W, Al Dorazi SA, Soames R. The origin variability of the iliolumbar artery and iatrogenic sciatica. Eur J of Orthop Sur traumatol. 2015;25(1):199-204.

[10] Kostov S, Kornovski Y, Slavchev S, Ivanova Y, Dzhenkov D, Dimitrov N, et al. Pelvic lymphadenectomy in gynecological oncology-significance of anatomica variations. Diagnostics. 2021;11(1):89.

[11] Lipshutz B. A composite study of the hypogastric artery and its branches. Ann Surg. 1981;67(5):584-608.

[12] Gadagi RS, Mulage SK. The origin variability of the iliolumbar artery: A cadaveric study with clinical significance. Int J Anat Res. 2018;6(3.3):5708-12.

[13] Dzmitry V, Anastasiya B. Anatomical variation of iliolumbar artery and its clinical significance. Arch Biomed Eng \& Biotechnol. 2020;3(5):01-02.

[14] Kiray A, Akçalý O, Tayefi H, Kopay C, Ergür I. Anatomical variations of iliolumbar artery and its relation with surgical landmarks. Acta Orthop Traumatol Turc. 2010;44(6):464-68.

[15] Koç T, Gilan ÝY, Aktekin M, Kurtoðlu Z, Daðtekin A, Aytaç G, et al. Evaluation of the origin and branching patterns of the iliolumbar artery and its implications on pelvic and vertebral surgery. Saudi Med J. 2016;37(4):457-60.

[16] Yuvaraj MF, Balaji T, Rajila RHS, Vaithinathan G, Aruna S, Balaji K. Study on Variations in the origin and branching pattern of internal iliac artery in cadavers. Biome Pharmacol J. 2018;11(4).

\section{PARTICULARS OF CONTRIBUTORS:}

1. Junior Resident, Department of Anatomy, Goa Medical College and Hospital, Goa, India.

2. Assistant Professor, Department of Anatomy, Goa Medical College and Hospital, Goa, India.

3. Associate Professor, Department of Surgery, Goa Medical College and Hospital, Goa, India.

NAME, ADDRESS, E-MAIL ID OF THE CORRESPONDING AUTHOR:

\section{Medora CD Dias,}

Villa A17, Sapana Harmony, Gogol, Goa, India.

E-mail: drmedoradsouza@gmail.com
PLAGIARISM CHECKING METHODS: Jain Het al.]

- Plagiarism X-checker: Jan 12, 2021

- Manual Googling: Apr 14, 2021

- iThenticate Software: May 07, 2021 (8\%)
ETYMOLOGY: Author Origin

\section{AUTHOR DECLARATION:}

- Financial or Other Competing Interests: None

- Was Ethics Committee Approval obtained for this study? Yes

- Was informed consent obtained from the subjects involved in the study? NA

- For any images presented appropriate consent has been obtained from the subjects. NA
Date of Submission: Jan 11, 2021

Date of Peer Review: Feb 11, 2021

Date of Acceptance: Apr 27, 2021

Date of Publishing: Oct 01, 2021 